\title{
Ethical approval for research involving geographically dispersed subjects: unsuitability of the UK MREC/LREC system and relevance to uncommon genetic disorders
}

\author{
Julia C Lewis, Susan Tomkins and Julian R Sampson University of Wales College of Medicine, Cardiff
}

\begin{abstract}
Objectives-To assess the process involved in obtaining ethical approval for a single-centre study involving geographically dispersed subjects with an uncommon genetic disorder.

Design-Observational data of the application process to 53 local research ethics committees (LRECs) throughout Wales, England and Scotland. The Multicentre Research Ethics Committee (MREC) for Wales had already granted approval.

Results-Application to the 53 LRECs required 24,552 sheets of paper and took two months of the researcher's time. The median time taken for approval was 39 days with only seven (13\%) of committees responding within the recommended 21 days. In at least nineteen cases (36\%) a subcommittee considered the application. Thirty-three committees (62\%) accepted the proposal without amendments but, of the remainder, four (8\%) requested changes outside of the remit of LRECs.

Discussion-Difficulties still exist with the system for obtaining ethical approval for studies involving a single centre but with patients at multiple sites, as is often required for genetic observational research. As such studies differ from true multicentre studies, it may be advantageous to develop a separate and specific process of application to ensure that resources are not unnecessarily expended in the quest for ethical approval.

(fournal of Medical Ethics 2001;27:347-351)

Keywords: Research ethics; MREC; LREC
\end{abstract}

\section{Introduction}

Ethical safeguards are an essential component of research planning and the profile of research ethics was raised in the 1960 s with the publication of the World Medical Association's Declaration of Helsinki ${ }^{1}$ and Pappworth's Human guineapigs: experimentation in man. ${ }^{2}$ In 1967 the Royal College of Physicians recommended the routine ethical review of all research and the following year, a recommendation from the Department of Health suggested that hospitals set up ethical review boards. ${ }^{3}$ It was not until 1991, however, that this process was formalised and the responsibility for the ethical review of research was devolved from the Department of Health to local research ethics committees (LRECs).

Foster $^{5}$ felt that ethics committees should ask three basic questions when evaluating research:

1. Does the project ask an important question?

2. Are the risks to the research subjects acceptable?

3. Will the research subjects' autonomy be respected by obtaining consent?

Kent $^{6}$ suggested there were three areas for which LRECs were responsible:

1. The rights of the research participants (the most important);

2. Obligations towards society at large, and

3. Obligations towards researchers.

He then surveyed potential research subjects, researchers and LREC members regarding the relative importance of these three issues and found a variation in the opinions of the three groups. He pointed out that this could be a source of misunderstanding and lead to frustration in gaining ethical approval.

Although the LRECs were ideally placed to consider single-centre research, there were problems with the system for gaining multicentre approval. Redshaw et al commented that "The timing of data collection and analysis was affected by the cumbersome and unwieldy nature of the submission process and the multiple applications". The variations in working patterns between committees were considerable, reflecting the lack of any official guidelines before $1991 .^{\circ}$ Researchers undertaking a multicentre study had to apply to each of the relevant LRECs across the country. Some would grant approval on the basis of the initial letter only (particularly if the researchers' own LREC had already 
348 Research ethics: Ethical approval for research involving geographically dispersed subjects: unsuitability of the UK $M R E C / L R E C$ system and relevance to uncommon genetic disorders

approved the study), whilst others required submission of their own application form. These varied markedly between different committees. In one study it was found that only $43 \%$ of the information requested was common to half of the application forms. ${ }^{9}$ In addition, there was a variation in the number of copies requested, ranging from only one up to twenty. ${ }^{79}{ }^{10}$ In one study the application to one committee alone required 2,151 sheets of $\mathrm{A} 4$ paper. ${ }^{11}$

\section{Approval times}

Committees also varied in the frequency of their meetings, which was one of the reasons given for the wide range of approval times-anything from six to 300 days. $^{7-11}$ Severe criticisms of such long delays have been made in the past. It has been suggested that in one instance, the ISIS-2 trial of streptokinase and aspirin in myocardial infarction, patients' lives could have been saved, were it not for the protracted ethics committee procedures. ${ }^{12}$

Prior to granting approval, LRECs have been reported to demand changes ranging from the wording of patients' letters to the title of the project and it has been noted that some committees have idiosyncratic requirements. ${ }^{11}$ The most striking feature of reports concerning LREC approval for multicentre studies are the estimated costs both in time and money. Redshaw et al estimated a cost of $£ 4,000$ to apply to 24 committees, involving 280 hours of work time. Busby and Dolk found that it took a total of six person-weeks to complete their applications.

Likely causes of inconsistency between LRECs in dealing with multicentre proposals suggested by the commentators include the lack of updated national guidelines. Although guidance was given to the committees in 1991, there was little in the way of updates. This, combined with the fact that in many parts of the country there was little communication between LRECs, even between those within the same geographical area, led to the evolution of largely autonomous committees with individual interpretations of the general guidelines.

In 1997, the Department of Health set up multicentre research ethics committees (MRECs) in an attempt to ease the process of approval in multicentre studies. ${ }^{15}$ (Multicentre research was defined as that which took place over five or more LREC boundaries). To gain ethical approval for such a study the principal investigator was required to submit an MREC application form to a single MREC somewhere within the geographical area of the study (all MRECs share a common application form). Once the MREC granted approval, copies of this form were then to be sent to all relevant LRECs, whose executive subcommittees were to consider any local issues (for example local researchers, facilities and study population). Initial problems with the system led to further guidelines being issued from the Department of Health and the National Health Service (NHS) executive, regarding the precise role of local committees. These suggested that executive subcommittees should be established to consider applications already accepted by MRECs within two weeks of receipt of an application and that the process should be completed in no more than 21 days. Rejection of an application by a LREC could only be for local reasons and no other changes to information sheets or consent forms could be made. It was hoped that this system would ease the process of approval for multicentre studies. Recent reports suggest, however, that there might still be room for improvement. ${ }^{16-18}$

This paper reports on recent experience of gaining ethical approval for observational research into a rare genetic disorder (tuberous sclerosis). In studying such conditions it is often necessary to consider a geographically dispersed study population if one is to include enough subjects to make the results meaningful. Within the current system for ethical approval this requires application to both the MREC and the many LRECs representing all the subjects in the study population. In conditions where patients are scattered geographically this can mean that there will be as many LRECs as there are subjects. In observational studies that do not require local researchers or local facilities, this process seems unnecessary. The cost of such a lengthy application process presents a considerable financial burden.

\section{Methods}

Ethical approval was sought for the study, Genotype-Phenotype Correlations in Tuberous Sclerosis, which sought to assess clinical and psychological aspects of disease severity in a cohort of 150 subjects from across Britain who had been previously investigated for mutations in the tuberous sclerosis complex 1 (TSC1) and tuberous sclerosis complex 2 (TSC2) genes. ${ }^{19}$ We proposed contacting the subjects or their parents or carers, requesting consent for the study and, for those providing consent, undertaking a review of medical records including imaging studies, clinical examination and a battery of psychological tests assessing IQ, behaviour and psychiatric symptoms. Patients would be seen in our clinics or, if living outside Wales, at their homes. In a small proportion of cases in whom no mutation had been identified, a further blood sample would be requested for genetic analysis. The study design was not truly multicentre as we were not involving different researchers at each site. It would probably be best described as "multiple site" research, describing the dispersion of the patients rather than the research staff.

In line with current NHS executive guidelines, as our study encompassed an area of more than five LRECs, we initially applied to the MREC for Wales in August 1998. Once approval had been granted, we then applied to the relevant LRECs for local approval. Each of the LRECs had to be contacted by telephone to ensure that address details and the number of copies of the application forms required were correct (information originally supplied by the MREC). Local research ethics committees in Wales 
were contacted in November 1998. A change in staff meant that the project was temporarily suspended and that applications to English and Scottish LRECs were made between January and February 2000.

For the purposes of this study the time taken for approval was the time from the predicted date of receipt by the committee of the application packages to the receipt of the approval documents in the department. The predicted date of receipt was taken to be five days after the packages left our department.

Each LREC requested a variable number of copies of the application "package". The total number of pages per package was sixty-two.

\section{Results}

VOLUME OF PAPERWORK

Overall, application was made to 53 LRECs (seven in Wales, 38 in England and eight in Scotland). For most committees there were no more than two subjects in their area (range $1-18$, median of 1 ). The committees required between one and 24 copies of the 62-page application package (median 11), ie 62 to 1488 pages (median 620). As recommended by the MREC, the application package included the full MREC application form, copies of all the MREC correspondence, the study protocol, the project summary and a list of the assessment tools to be used. The total number of pages photocopied in order to apply to all the LRECs involved was 24,552 .

\section{RESOURCES REQUIRED}

Overall, the process of application for ethical approval took the clinical research fellow with secretarial support most of the first two months of the study. Our considerable photocopying requirements soon led to a departmental paper famine and we further annoyed the department by monopolising the photocopier which, at one stage, "gave up the ghost". It is a moot point whether, in an era of routine electronic communication, photocopying and collating 472 copies of a 62-page document should be considered an expensive waste of research time or a valuable lesson in the difficulties associated with the organisation of clinical research.

TIME TAKEN FOR APPROVAL

No major delays within the postal service were noted (by comparison of letter dates and dates of arrival).

Seventeen $(33 \%)$ of committees sent an initial acknowledgement letter and the time taken for this to arrive was between two and 45 days (median ten days). The time for approval varied between 12 days and 132 days (median 39 days). For those responding via executive sub-committee or chairman's decision (ie, "fast-track" committees) the median was 34 days. For full committee decisions the median was 42 days. Seven committees responded within the recommended twenty-one days $(13 \%)$.
COMMITTEE STRUCTURE

Seven replies from LRECs clearly stated that the decision had been by chairman's action (13\%). In 19 cases $(36 \%)$ the approval letter specified that the application had been reviewed by a subcommittee and in four cases $(8 \%)$ this was implied because they requested three or fewer copies (criteria used by Tully $\left.e t a l,{ }^{17}\right)$. In four cases despite the fact that a subcommittee reviewed the proposal, they requested more than ten sets of the application documents.

Seventeen committees stated the number of committee members present at the meeting (32\%). The numbers ranged from two to 18 .

\section{IDIOSYNCRASIES}

Thirty-three committees accepted the research proposal without amendment (62\%). Twenty requested at least one change to documentation, clarification of some issue or application to a further committee (for example trust board, trust research and development office). In four cases the changes requested were outside the remit of LRECs, for example changes to patient consent forms or patient letters. This involved further correspondence with the MREC for Wales for clarification of these issues.

Our protocol included correspondence to general practitioners and principal hospital clinicians informing them of their patient's involvement and offering further information regarding the study. Nevertheless, one committee asked that GPs be contacted for their consent prior to us contacting their patients whilst another asked us to seek the permission of consultants. One LREC asked that a patient information sheet outlining local contacts for further advice regarding involvement in research be sent to all the subjects in their area. Two of the committees also requested that we fill in a research and development form for their local office. One committee requested a handling fee of $£ 10$.

We were advised by the MREC that, as we were not utilising any local researchers or local facilities, we would not have to include an "Annex D" form with our LREC applications. (This form is normally used if the research involves separate researchers in each local area to carry out the project). However, three committees insisted that an "Annex D" be sent before the application could be considered and a further committee stated that they had contacted the MREC for Wales with regard to the "Annex D" form but were satisfied with the reply.

\section{Discussion}

It has been noted that questionnaire- and interview-based studies cause particular difficulty during ethical committee review ${ }^{3}$ as the current system is designed to deal primarily with intervention studies. Advice given to LRECs in 1991 was almost entirely focused on drug trials and included no information on genetic research. In response to 
350 Research ethics: Ethical approval for research involving geographically dispersed subjects: unsuitability of the UK $M R E C / L R E C$ system and relevance to uncommon genetic disorders

enquiries from LRECs regarding the approval of genetic research, the Advisory Committee on Genetic Testing provided a guidance document ${ }^{20}$ containing information on several issues specific to research involving genetic testing.

\section{VOLUME OF PAPERWORK}

We found that, although the MREC/LREC system obviates the need to complete many differen LREC application forms, instead requiring provision of copies of a single MREC application form, this has not significantly reduced the volume of paper involved. A median of 11 copies was required per LREC. This observation is surprising given the Department of Health guidelines recommending that an executive subcommittee should consider such proposals rather than a full LREC committee. ${ }^{15}$

\section{TIME TO APPROVAL}

As in previous reports we found a wide range in approval times. In total $13 \%$ of the sample dealt with our application within the recommended 21-day period. In some cases, even the acknowledgement letter did not reach us within 21 days. This proportion is much lower than that reported in other studies $\left(31 \%\right.$ by Tully et al, ${ }^{17} 33 \%$ by Lux et $\left.a l^{18}\right)$. The reasons for this are not known although the possibility exists of variations in committee workload at the time when we submitted our applications.

Overall, the median time to approval that we observed (39 days) was comparable to median times found in other studies $(58$ days by Larcombe and Mott, ${ }^{16} 41$ days by Tully et al, ${ }^{17}$ and 28 days by Lux et $a l^{18}$ ). Breaking down the approval times on the basis of committee type, our results are also comparable to those of Tully et $a l^{17}$ who found medians of 28.5 days for fast-track committees (this study 34 days) and 46 days for full committees (this study 42 days). However, Lux et $a l^{18}$ reported medians of 30 days for fast-track and 25 days for full committees. Together, these studies indicate that a large number of LRECs do not follow the Department of Health guideline that, for MREC-approved studies, a meeting of an executive subcommittee should be called within two weeks of receipt of the application. Instead these applications are often being placed on the agenda for the next regular meeting of the full committee and, as these generally occur on a monthly basis, this can be one source of delay.

\section{RECOMMENDATIONS}

The current system for ethical approval is geared more towards interventional studies than observational genetic research. Greater scope or flexibility within the system is required if it is to be appropriate for the diversity of current research. For studies involving geographically dispersed subjects, application to the MREC should remain the first step in the process but a simpler process for the individual LRECs would improve the process. A common document, perhaps from the MREC, outlining their reasons for granting approval together with a section that can be completed by the researchers to outline any issues relevant to the LREC would conserve both time and resources. In cases where local facilities are to be used it seems reasonable that the application be considered by the LREC. In cases where no local facilities are involved, however, there seems little point in one committee considering a study that has already been approved by another. Such changes would not lead to any loss in the quality of ethical review but would ease the process for researchers and reduce the workload of LRECs.

In November 2000 the Central Office for Research Ethics Committees (COREC) produced an operational modification of the system of ethical review for multicentre studies where there is no need for a local researcher. ${ }^{21}$ It is expected that this would occur in five different circumstances, one of which would be the development of a patient database with subsequent patient contact. The document states that the ethical aspects of the research should be considered by the MREC and the LREC then informed of the project and the name and contact details of any local clinician involved. The LREC does not need to approve the project. The MREC would provide standard format letters for the researchers to use when informing the relevant branches of the NHS (LRECs and NHS management if using NHS premises). In theory this modification holds great promise for the streamlining and increased flexibility of the current system and should address many of the issues raised in this paper. It remains to be seen how useful it will be in practice and how quickly it becomes the standard procedure.

\section{Conclusions}

It was hoped that the development of the MREC system would serve to streamline and fast-track the process of obtaining ethical approval for research proposals involving five or more LRECs. However, our experience, and that of others, suggests that this is not, as yet, the case. ${ }^{16-18} 22$

Although MRECs have obviated the need for completion of different forms for each LREC, many of whom now follow a subcommittee procedure, there is still scope for reduction of paperwork and time to approval. The unsuitability of the current MREC/LREC system for "multisite" as opposed to "multicentre" research is of particular relevance in small research programmes into rare disorders, such as Mendelian diseases, that require wide geographic ascertainment but have limited administrative resources available.

Undoubtedly, the task facing LRECs is not easy. They perform the valuable roles of protecting the interests of potential subjects in their areas and encouraging the practice of sound research. It is likely that the workloads of the different committees vary as well as the quality and complexity of submitted proposals, making a consistent approach difficult to maintain. Some committees have 
perceived articles describing the difficulties of the approval process as being "repetitious criticism". We feel, however, that the difficulty lies not with individual committees, but with the process as a whole. It is hoped that the changes suggested by the COREC will improve the process of ethical approval for multisite research.

\section{Acknowledgements}

JCL is funded by the Tuberous Sclerosis Association. Cyril Chapman provided helpful advice on the manuscript.

Fulia $C$ Lewis, BSc, MBBS, MRCGP, MRCPsych, $M S c$, is Clinical Research Fellow and Honorary Specialist Registrar in Psychiatry in the Institute of Medical Genetics, University of Wales College of Medicine, Heath Park, Cardiff. Susan Tomkins MB, ChB, MRCP, is currently Consultant in Medical Genetics in the Department of Clinical Genetics, St Fames'University Hospital, Leeds and fulian R Sampson, DM, FRCP, is Professor of Medical Genetics in the Institute of Medical Genetics, University of Wales College of Medicine, Heath Park, Cardiff.

\section{References}

1 Gilder S. WMA meets in Helsinki. British Medical fournal. 1964;ii:299-300.

2 Pappworth MH. Human guineapigs: experimentation on man. London: Routledge and Kegan Paul, 1967.

3 Alberti K. Multicentre research ethics committees: has the cure been worse than the disease? British Medical fournal 2000;320 $1157-8$.

4 Department of Health. Local research ethics committees. Health service guidelines. London: Department of Health, 1991: HSG(91) 5 .

5 Foster C. Why do research ethics committees disagree with each other? Fournal of the Royal College of Physicians of London 1995;29:315-18

6 Kent G. The views of members of local research ethics committees, researchers and members of the public towards committees, researchers and members of the public towards
the roles and functions of LRECs. Fournal of Medical Ethics the roles and func

7 Redshaw ME, Harris A, Baum JD. Research ethics committee audit: differences between committees. Fournal of Medical Ethics 1996;22:78-82.
8 Ahmed A, Nicholson K. Delays and diversity in the practice of local research ethics committees. Fournal of Medical Ethics 1996;22:263-6.

9 Busby A, Dolk H. Local research ethics committees' approval in a national population study. Fournal of the Royal College of Physicians of London 1998;32:142-5.

10 Ah-See K, Mackenzie J, Thakker N, Maran A. Local research ethics committee approval for a national study in Scotland. fournal of the Royal College of Surgeons of Edinburgh 1998;43: 303-5.

11 White AE. Research ethics committees at work: the experience of one multilocation study. Fournal of Medical Ethics 1996;22: 352-5.

12 Meade TW. The trouble with ethics committees. fournal of the Royal College of Physicians of London 1994;28:102-4.

13 Stacey TE. Ethical review of research in the NHS: the need for change. Fournal of the Royal College of Physicians of London 1998;32:190-2.

14 Holley S, Foster C. Ethical review of multicentre research: a survey of local research ethics committees in the South Thames region. Fournal of the Royal College of Physicians of London 1998; 32:238-305.

15 NHS Executive. Ethics committee review of multicentre research. London: NHS Executive, Apr 1997. HSG(97)23, April 1997.

16 Larcombe I, Mott M. Multicentre research ethics committees: have they helped? Fournal of the Royal Society of Medicine 1999; 92:500-1.

17 Tully J, Ninis N, Booy R,Viner R. The new system of review by multicentre research ethics committees: prospective study. British Medical fournal 2000;320:1179-82.

18 Lux A, Edwards S, Osborne J. Responses of local research ethics committees to a study with approval from a multicentre research ethics committee. British Medical fournal 2000;320: 1182-3.

19 Jones A, Shyamsundar M, Thomas M, Maynard J, Idziaszczyk, Tomkins S, et al. Comprehensive mutation analysis of TSC1 and TSC2-and phenotypic correlations in 150 families with tuberous sclerosis. American fournal of Human Genetics 1999;64:1305-15.

20 Advisory Committee on Genetic Testing. Third annual report and compendium of guidance, fanuary 1999-December 1999. London: Health Departments of the United Kingdom, May 2000.

21 Central Office for Research Ethics Committees. Supplementary operational guidelines for NHS research ethics committees. London: Central Office for Research Ethics Committees, 2000.

22 Al-Shahi R, Warlow CP. Ethical review of a multicentre study in Scotland: a weighty problem. Fournal of the Royal College of Physicians of London 1999;33:549-51.

23 Alexander J. Multicentre research ethics committees. Fournal of the Royal Society of Medicine 1999;92:662.

\section{News and notes}

\section{Life without Disease: Advanced European Bioethics Course}

This year's Advanced European Bioethics Course, Life without Disease, will be held from 15 - 17 November in Nijmegen, the Netherlands.

Subjects will include: stem cell research; xenotransplantation; tissue engineering; cloning; reproductive planning, and pharmacogenetics.
For more information contact: N Steinkamp, Catholic University Nijmegen, 232 Department of Ethics, Philosophy and History of Medicine, PO Box 9101, 6500 HB Nijmegen, the Netherlands. Tel: int. 31-243615320; fax: int. 31-24-3540254; email: n.steinkamp@efg.kun.nl 